\title{
Polycyclic Aromatic Hydrocarbons Have Adverse Effects on Benthic Communities in the Baltic Sea: Implications for Environmental Status Assessment
}

\author{
Caroline Raymond ${ }^{1}$, Elena Gorokhova ${ }^{2}$ and Agnes ML Karlson ${ }^{1,3 *}$ \\ ${ }^{1}$ Department of Ecology, Environment and Plant Sciences (DEEP), Stockholm University, Stockholm, Sweden, ${ }^{2}$ Department \\ of Environmental Science, Stockholm University, Stockholm, Sweden, ${ }^{3}$ Stockholm University Baltic Sea Centre, Stockholm, \\ Sweden
}

OPEN ACCESS

Edited by:

Andrew Hursthouse University of the West of Scotland, United Kingdom

Reviewed by: Federica Nasi, National Institute of Oceanography and Applied Geophysics (Italy), Italy Abdolvahab Maghsoudlou, Iranian National Institute for Oceanography and Atmospheric

Science, Iran

*Correspondence: Agnes ML Karlson agnes.karlson@su.se

Specialty section: This article was submitted to Toxicology, Pollution and the Environment

a section of the journal Frontiers in Environmental Science

Received: 31 October 2020 Accepted: 17 March 2021 Published: 12 April 2021

Citation:

Raymond C, Gorokhova E and Karlson AML (2021) Polycyclic Aromatic Hydrocarbons Have

Adverse Effects on Benthic

Communities in the Baltic Sea: Implications for Environmental Status

Assessment.

Front. Environ. Sci. 9:624658. doi: 10.3389/fenvs.2021.624658
Changes in benthic macrofaunal communities are indicative of environmental stressors, including eutrophication and hypoxia. However, some species are sensitive not only to hypoxia but also to various environmental contaminants. We tested which of the environmental predictors (sediment organic carbon, sediment concentrations of metals and polyaromatic hydrocarbons [PAHs], bottom water oxygen, salinity, temperature, and surface chlorophyll-a concentration) that best explained the following response variables: (1) macrofauna community composition, (2) abundance of a benthic sentinel species, the amphipod Monoporeia affinis; and (3) the Benthic Quality Index (BQI). All data originated from 29 reference monitoring stations in the Baltic Sea and the statistical tests included both uni- and multivariate analyses. The community composition and BQI were best explained by the same combination of salinity, depth, temperature and PAH concentrations. The abundance of $M$. affinis, which is sensitive to hypoxia and chemical exposure, was best explained by PAHs as a single predictor. Our findings suggest that benthic communities in the Baltic Sea are influenced by anthropogenic contaminants, which should be taken into account when benthos is used for eutrophication status assessment.

Keywords: environmental quality, hazardous substances, seafloor integrity, sediment, key-species, zoobenthos, biodiversity, contaminants

\section{INTRODUCTION}

Anthropogenic impacts, such as pollution with nutrients and hazardous substances, together with the progressing climate change threaten biodiversity and ecosystem integrity worldwide (Halpern et al., 2008; Cloern et al., 2016). Benthic communities in marine soft sediments, the world's second largest habitat, are increasingly subjected to multiple stressors resulting from these pressures. Hypoxia as a consequence of eutrophication, and to some extent increasing temperatures, are considered the major threat (e.g., Breitburg et al., 2018; Ehrnsten et al., 2020). In coastal environments, benthic ecosystems are also commonly exposed to contaminant loading. Benthic communities, hereafter macrobenthos, respond relatively fast to environmental 
disturbances but with species-specific sensitivity/tolerance to stressors (Pearson and Rosenberg, 1978). The composition of macrobenthos integrates environmental conditions over longer periods (years to decades). Therefore, macrobenthos is commonly used as indicators of ecosystem status and health (Pearson and Rosenberg, 1978; Dauer, 1993; Borja et al., 2000; Muniz et al., 2005).

The Baltic Sea is strongly influenced by eutrophication and contaminants and is often considered one of the most polluted sea areas in the world (Elmgren, 1989; Karlson et al., 2002; Belkin, 2009; Carstensen et al., 2014). In addition, it has a naturally low species richness due to its low salinity (Elmgren, 1984), and it is one of the most studied ecosystems making it suitable for potential future scenarios for other sea areas (Elmgren and Hill, 1997; Reusch et al., 2018). The restricted water exchange from the permanent halocline and seasonal pycnoclines in coastal water results in a natural oxygen deficiency, which is exacerbated by eutrophication (Conley et al., 2009, 2011; Carstensen et al., 2014). Anoxia has increased several-fold since the early 1990s, leading to the elimination of macrobenthos below the halocline at 70-80 m depth in the Baltic Proper (Karlson et al., 2002; Conley et al., 2009, 2011), but also shallower areas can be exposed to seasonal or episodic hypoxia (Gammal et al., 2017). Increasing organic enrichment and hypoxia are likely to alter macrobenthic species composition via differential effects on sensitive and tolerant species (Pearson and Rosenberg, 1978). However, in the species-poor Baltic Sea, such changes in species composition due to variability in oxygen concentrations have not been found significant (e.g., Villnäs and Norkko, 2011; Rousi et al., 2013). Nevertheless, macrobenthos and various metrics based on the community structure are broadly used as indicators of ecological effects of eutrophication with low oxygen conditions being considered the primary cause for potential changes in species composition (HELCOM, 2009; Leonardsson et al., 2009).

The Water Framework Directive (WFD) and Marine Strategy Framework Directive (MSFD) provide a general framework to evaluate the environmental quality of biological, hydromorphological, and physicochemical characteristics of water bodies in Europe (Council directive 2000/60/EC). Assessing the environmental quality of soft-bottom macrofauna in coastal and open sea areas differs between countries bordering the Baltic Sea and its sub-basins (HELCOM, 2009) since the strong salinity gradient and habitat types determine the species diversity (Elmgren, 1984; Leppäkoski and Bonsdorff, 1989; Rumohr et al., 1996). Thus, no single index has been applicable to capture these differences, and each country uses different benthic community metrics to assess the state of the environment. In the northern Baltic Proper and the Bothnian Sea, where Sweden and Finland are the bordering countries, two similar indices are used for assessment of benthic quality: Sweden uses Benthic Quality Index (BQI), and Finland uses Brackish-water Benthic Index (BBI) (Perus et al., 2007; HELCOM, 2009, 2018b; Leonardsson et al., 2009). Both indices build on abundance weighted proportion of sensitive to tolerant taxa and the number of species within the community, and good benthic quality is associated with a high proportion of sensitive taxa and a high number of species. The species sensitivity values are primarily based on tolerance to low oxygen levels and not to other stressors, such as environmental contaminants.

Organic contaminants and heavy metals are, however, considered major threats to the Baltic Sea (HELCOM, 2010). Many environmental contaminants remain in the Baltic Sea for a long time because of the slow water exchange (Meier, 2007), the persistent nature of many pollutants, and the association of hydrophobic chemicals to sediments (Axelman et al., 2001). In particular, polycyclic aromatic hydrocarbons (PAHs) and heavy metals cause various adverse effects on macrobenthos (Sundelin, 1983; Long et al., 1995; Landrum et al., 2003; Martins et al., 2013; Löf et al., 2016). The amphipods Monoporeia affinis and Pontoporeia femorata are key components in the benthic communities, ranked among the most hypoxia-sensitive species, but their reproduction and embryo development are also highly sensitive to contaminants (Sundelin and Eriksson, 1998). In the MSFD, embryo development of $M$. affinis is, therefore, used as a supplementary indicator of biological effects of contaminants (HELCOM, 2018a).

Here, we tested which of the environmental predictors (sediment organic carbon, sediment concentrations of metals and PAHs, bottom water oxygen, salinity, temperature, and surface chlorophyll-a concentration) that best explained the following response variables: (1) macrobenthic species composition, (2) abundance of a macrobenthic sentinel species, the semelparous amphipod Monoporeia affinis (life cycle of 2 years); and (3) the Benthic Quality Index (BQI). The data originated from 29 monitoring stations located along the Swedish Baltic Sea coast with no known point sources of pollution.

We specifically asked three questions.

(1) Can variability in the macrobenthic species composition be better explained by including contaminant data to environmental variables?

(2) Can variability in the abundance of the sentinel species Monoporeia affinis be better explained by including contaminant data?

(3) Does the benthic quality index (BQI), aimed for assessing eutrophication effects, also correlate with sediment contaminant levels?

\section{MATERIALS AND METHODS}

\section{Site Descriptions and Study Species}

The Baltic Sea is a semi-enclosed non-tidal brackish water body, the largest in the world area-wise. The two largest basins are the Baltic Proper (BP) and the Bothnian Sea (BoS) (Figure 1). The Baltic Sea is characterized by a permanent salinity gradient that is decreasing northwards and a permanent halocline at about $80 \mathrm{~m}$ depth in the Baltic Proper. The low salinity with mean surface salinity of 6-7.5 and 4-5 in BP and BoS, respectively, and the short evolutionary time because of the recent geological history, have resulted in a uniquely low species richness of benthic macrofauna (Elmgren and Hill, 1997).

The soft-bottom communities in the Baltic Sea deeper than $20 \mathrm{~m}$ are thus represented only by a handful species, where 


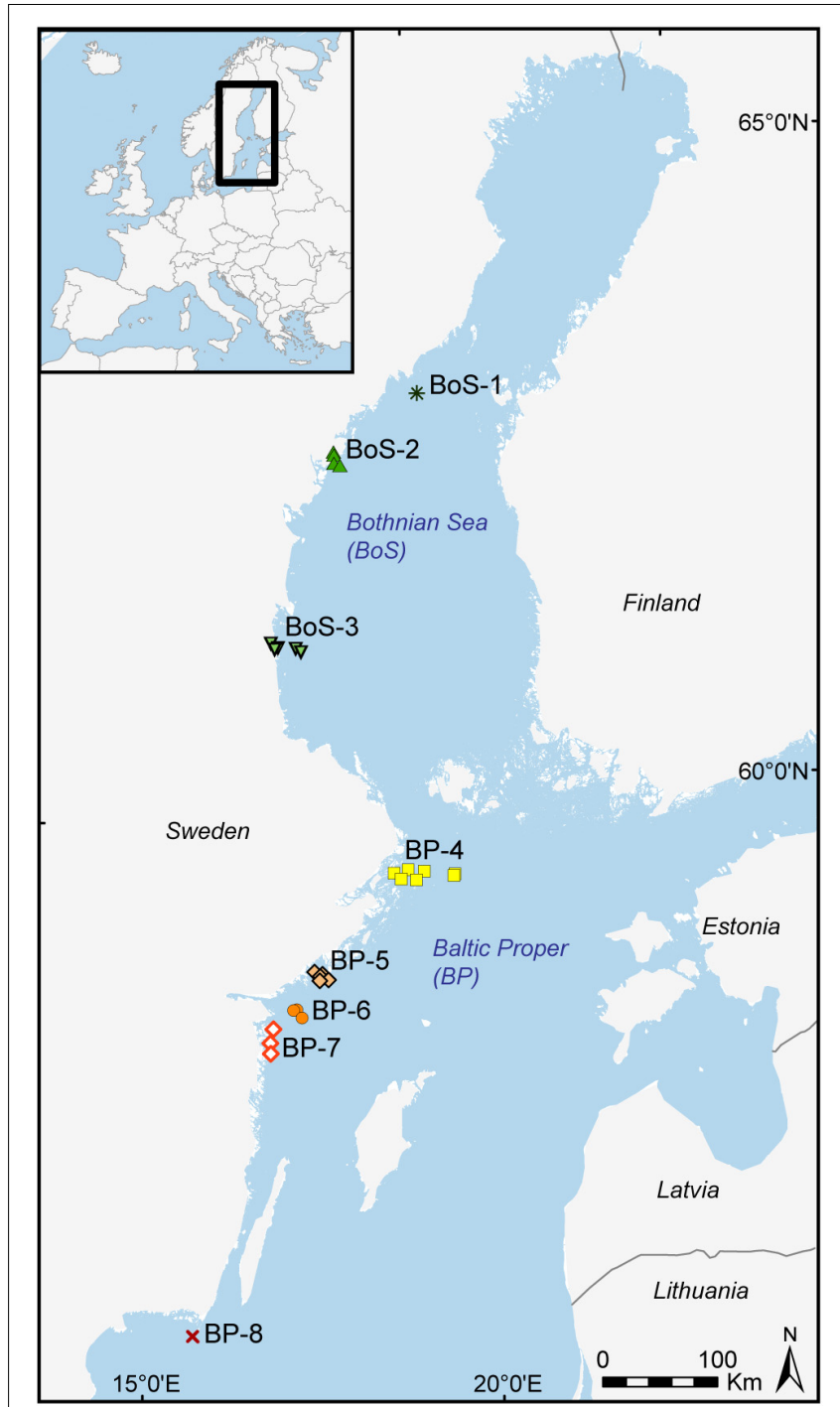

FIGURE 1 | The 29 stations (color-coded) within regions along the Swedish Baltic Sea coast. Regions 1-3 in the Bothnian Sea (BoS) and regions 4-8 in the Baltic Proper (BP). The Swedish names for the regions (and number of stations included in each region) are as follows; BoS-1 Norrbyn (1 station), BoS-2 Höga kusten (4 stations), BoS-3 Söderhamn (5 stations), BP-4 Stockholm (7 stations), BP-5 Askö (5 stations), BP-6 Hävringe (3 stations), BP-7 Östergötland (3 stations), and BP-8 Utklippan (1 station).

the long-lived (up to 30 years; Segerstråle, 1960) tellenid clam Limecola balthica (previously known as Macoma balthica) often dominates the biomass, except for the northernmost parts. Two species of semelparous amphipods with a 2 year life-cycle, Monoporeia affinis (a glacial relict) and the morphologically similar Pontoporeia femorata (of marine origin), often dominates the abundance in the Baltic Proper although in lower numbers now than in the 1970s (Ankar and Elmgren, 1976; Rousi et al., 2013). In the Bothnian Sea, M. affinis dominates the depositfeeding guild. In recent decades, the non-indigenous polychaetes Marenzelleria (three morphologically similar species; Bastrop and Blank, 2006) have successfully colonized the entire Baltic Sea, and since the early 2000s, it is a dominant genus (Kauppi et al., 2015). The most abundant predatory invertebrates in the Baltic Proper are the isopod Saduria entomon, the polychaete Bylgides sarsi, and the priapulid Halicryptus spinulosus; the latter two are of marine origin and less abundant in the Bothnian Sea.

\section{Sampling Methods and Data Extraction}

Macrobenthos was collected within the Swedish National and Regional monitoring program for benthic macrofauna with a yearly (May to early June) sampling along the Swedish coast. One van Veen grab sample $\left(0.1 \mathrm{~m}^{2}\right)$ is collected at each station, sieved onboard over a $1 \mathrm{~mm}$ mesh, and the retained material is fixed with $4 \%$ buffered formaldehyde. High spatial coverage instead of replication within stations is recommended for Baltic macrobenthic monitoring (SEPA, 2007); variation between replicate samples in this species-poor system is low, and species rarefaction curves are nearly saturated after a single sample (Villnäs and Norkko, 2011). The macrobenthic organisms are identified to the lowest possible taxonomical level in the lab, counted, and weighed (see species list in Supplementary Table 2). The sampling, sample processing, and taxonomic analysis follow the European standard (CSN EN ISO 16665, 2013).

Sediment samples were collected within the program for biological effect monitoring of contaminants, carried out since 1994 in the Swedish Baltic Sea coastal areas by assessing embryo development in the sentinel amphipod species $M$. affinis and $P$. femorata. The sampling is conducted in January, when gravid females can be obtained (Sundelin and Eriksson, 1998; Sundelin et al., 2008; HELCOM, 2018a) using a benthic sledge set to sample the upper $2-3 \mathrm{~cm}$ of the sediment. From the year 2012, the effect monitoring was expanded to cover a larger geographical region and improve the spatial overlap with the Swedish National and Regional monitoring program for benthic macrofauna. As a result, 30 matching stations within the benthic macrofauna monitoring program were established. One station (SR1A, BoS3 region) was populated only by $M$. affinis at ten-fold higher densities than the median density; hence, it was considered an outlier and excluded from all statistical analyses. Thus, the study is restricted to 29 stations; 10 of them located in the Bothnian Sea and 19 stations in the Baltic Proper. For visualization, these stations are grouped into eight regions dependent on their latitude; Figure 1. All stations included in this study (Supplementary Table 1) are representing areas without any known point sources of pollution.

Salinity, temperature and oxygen concentrations are measured simultaneously in the bottom water when the macrobenthic sampling is carried out; however, these data represent only a snapshot of these abiotic variables. Moreover, there is no sampling of Chlorophyll-a (Chl-a) from the monitoring stations used in this study. We, therefore, extracted modelled environmental data from DAS (Data Assimilation System ${ }^{1}$; Sokolov et al., 1997; Savchuk, 2018), which is a program that constructs a 3D grid of hydrographic and chemical monitoring data collected from all countries around the Baltic, stored

\footnotetext{
${ }^{1}$ http://nest.su.se/das
} 
in a database at the Stockholm University Baltic Sea Centre. Extrapolated data for our 29 stations and a relevant period (see below) are based on interpolations of data from varying spatial resolution across time (Supplementary Table 1 and Supplementary Figure 1). Temperature, salinity, and oxygen concentrations from August-October, the time of the year when oxygen minimum and temperature maximum could be expected to affect macrobenthos the following spring, were extracted from the bottom water for each site; note that the bottom depth varies across stations (Supplementary Table 1). In the upper part of the water column $(0-10 \mathrm{~m})$, the Chl- $a$ concentrations in spring (average March-May) and summer (average June-August) was extracted from each site. As there was not enough Chl$a$ data in the Bothnian Sea during the springtime to allow sufficient resolution for site-specific values in this basin, the spring Chl- $a$ was only used for analyses in the Baltic Proper (Supplementary Figure 1).

\section{Chemical Analyses}

The surface sediment samples from each station were immediately frozen $\left(-20^{\circ} \mathrm{C}\right)$. Samples of $20 \mathrm{mg}$ were analyzed for total organic carbon (TOC; $\mathrm{g} \mathrm{kg}^{-1}$ dry weight [dwt]) content after drying and homogenization. The TOC values were determined using a Flash 2000 (Thermo Scientific) elemental analyser at Stockholm University, Dept. Ecology, Environment and Plant Science, and expressed as a percentage per dry weight (dwt). Acidification is not necessary since the inorganic carbon content of Baltic sediment is negligible (J. Walve, Stockholm University, pers comm).

About $50 \mathrm{~g}$ of the frozen sediment were used for metal analyses (As, Cd, Co, Cr, Cu, Hg, Ni, Pb, V and $\mathrm{Zn}$ ) at ALS Scandinavia, Sweden, and the same amount of sediment for PAH analyses (11 priority congeners; SEPA, 1999; Josefsson, 2017) at the Swedish Environmental Research Institute (IVL), Gothenburg, Sweden. For three stations, the sediment from the year 2012 was lost during the sample processing; therefore, sediment from the year 2014 from the same station and same sampling month was used instead (Supplementary Table 1). Since the sediment is collected with a sledge, which integrates material from approximately 2$3 \mathrm{~cm}$, the measured contaminants and organic carbon content represent the conditions in this top layer, regardless of the yearly representation within this short period of time (2 years). Metal concentrations are expressed as mg per gram dwt sediment and PAHs as $\mu$ g per gram dwt sediment (Supplementary Tables 3, 4).

The measured concentrations of PAHs were compared to the Swedish sediment quality guidelines for PAHs in Baltic sediments (SEPA, 1999; Josefsson, 2017). PAHs are classified on a 5-grade scale, from insignificant to very high deviation established for both individual PAHs and the sum of 11 priority PAHs (SEPA, 1999; Josefsson, 2017). For metals, we used the risk quotient (RQ) approach. Here, the measured environmental concentration (MEC) is compared to the reference sediment values in Löf et al. (2016). The MEC-to-reference values ratio is the RQ, and RQ exceeding 1 for a metal suggests that it may pose a toxicity risk to the environment (EFSA, 2013; Arias-Andres et al., 2018). The sum of these RQ values was calculated for each station and used in statistical analyses since all metals correlated significantly and highly to RQ (Pearsons $r \geq 0.90$ except for As, $\mathrm{Hg}$ and Co, which had values of 0.73-0.89; Supplementary Table 6) and to each other (mean $r=0.80$, with only exception being As and $\mathrm{Hg}$, which were not significantly correlated; Supplementary Table 6). Similarly, all individual PAHs correlated significantly and highly to sum PAHs (Pearsons $r \geq 0.86$ except for anthracene with $r=0.70$; Supplementary Table 5), and all PAHs were significantly correlated to each other (mean $r=0.80$, except for anthracene and benso(k)fluoranthene, which were not significantly correlated; Supplementary Table 5). Threshold values based on benthic toxicity data, so-called Environmental

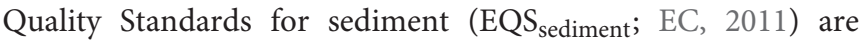
available for four compounds; the PAHs anthracene $\left(24 \mu \mathrm{g} \mathrm{kg}^{-1}\right.$ $\mathrm{dwt}$, standardized for 5\% TOC) and fluoranthene $\left(2,000 \mu \mathrm{g} \mathrm{kg}^{-1}\right.$ $\mathrm{dwt}$, for 5\% TOC) and the metals $\mathrm{Pb}$ and $\mathrm{Cd}$ (120 and $2.3 \mathrm{mg} \mathrm{kg}^{-1}$ dwt, respectively, not TOC standardized). The EQS sediment $_{\text {values }}$ were compared to our measured concentrations (standardized for TOC when relevant).

\section{Macrobenthic Index Calculation}

The Benthic Quality Index (BQI) based on the abundanceweighted proportion of sensitive to tolerant taxa and the number of species within the community was calculated for each station and used as a univariate response variable in statistical analyses as described in section "Statistical Analyses". The BQI index is defined as:

$$
\begin{aligned}
& B Q 1=\left[\sum_{i=1}^{{ }^{S} \text { classified }}\left(\frac{N_{i}}{N_{\text {classified }}} * \text { Sensitivity value }_{i}\right)\right] * \\
& \log _{10}(S+1)^{*}\left(\frac{N}{N+5}\right)
\end{aligned}
$$

where $S_{\text {classified }}$ is the number of taxa having a sensitivity value, $\mathrm{N}_{i}$ is the number of individuals of taxon $\mathrm{i}, \mathrm{N}_{\text {classified }}$ is the total number of individuals of taxa having a sensitivity value, the Sensitivity value ${ }_{i}$ is the sensitivity value for taxon $i, S$ is the total number of taxa, and $\mathrm{N}$ is the total number of individuals in the sample $\left(0.1 \mathrm{~m}^{2}\right)$. The species are classified on a sensitivitydisturbance scale, based on the species oxygen tolerance reported in the literature and expert knowledge (Leonardsson et al., 2009).

\section{Statistical Analyses}

The macrobenthic data were restricted to the stations with available contaminant data (BP: 19 stations, and BoS: 10 stations). We carried out ordinations, permutational variance analyses, and regression analyses as described in the following steps.

\section{Step 1: Establishing Gradients in Macrobenthic and Environmental Data}

First, the macrobenthos data from 2011-2014 were used to test whether the year 2012 was a representative year regarding the community composition. The year 2012 was of special interest for macrobenthos because of the high resolution Chl- $a$ and physicochemical data available from summer 2011 (lagged effect on benthos) and benthic contaminant data available from 2012 (see section "Sampling Methods and Data Extraction"). 
To visualize the variability in the macrobenthos abundance related to the region and sampling year, we used non-metric multidimensional scaling (nMDS; Clarke and Gorley, 2006), based on the Bray-Curtis similarity index. The abundance data were non-transformed prior to creating the resemblance matrix since subtle changes in dominant species are relevant. However, for comparison, all analyses are also performed on fourth-root transformed data downweighing dominant species (Supplementary Figure 2). Species composition (based on Bray-Curtis similarity index) was tested for the effect of Year (four levels; 2011, 2012, 2013, and 2014) and Region (eight levels; see map in Figure 1) and their interaction (Year $x$ Region) using Permutational analyses of variance, PERMANOVA (PERMANOVA + in PRIMER v6; Anderson, 2001). As a complement, to test for differences in beta-diversity among Regions, Jaccard similarity index on presence/absence data was also calculated and used in PERMDISP (Anderson et al., 2006).

Thereafter, multidimensional scaling using principal coordinate analysis (PCO) was performed on the species composition (based on the Bray-Curtis dissimilarity of abundance data) for the year 2012 only (since the analysis above confirmed that it was a representative year) and, separately on the environmental/chemical data (Euclidean Distance). We considered species and environmental data with a Spearman correlation greater than 0.3 with any of the first two ordination axes as significantly contributing to the differences between the stations. For all data types (abundances, environmental, and chemical data), the stations were grouped and visualized by Region as shown in Figure 1.

\section{Step 2: Linking Macrobenthic Data to Environmental Data}

Distance-based linear models (DistLM in PERMANOVA + for PRIMER 6; Anderson et al., 2008) is a multiple regression modeling, where the resemblance matrix (here the Bray-Curtis distances for species composition) is regressed against a set of explanatory variables. As shown in step 1, the year 2012 was representative for macrobenthic community development and, therefore, the abundance data for this year were used as response variable in DistLM analyses with environmental data for 2011 that were extracted from DAS (section "Sampling Methods and Data Extraction") and contaminant levels (section "Chemical Analyses") as explanatory variables. The time spans of the environmental and contaminant data were considered as ecologically relevant for the benthic community data from the monitoring survey 2012. The univariate responses for the abundance of Monoporeia affinis (recorded at all stations; resemblance based on the Bray-Curtis dissimilarity) and the BQI index (resemblance based on the Euclidean distance) were also analyzed by the DistLM.

The skewness of the explanatory variables was inspected using pair-wise Draftsman plots prior to analysis. The explanatory variables were generally not strongly correlated to each other (Anderson et al., 2008), and distributions were not strongly skewed (Supplementary Table 7). To validate the robustness of the results, both non-transformed and log-transformed contaminant concentrations were tested as predictors. Similarly, we also run all models with fourth-root transformed community composition data, which downweigh the importance of dominant species as stated in Step 1. Finally, as no spring Chl- $a$ data were available for the BoS, a model with spring Chl- $a$ data as an additional explanatory variable was analyzed for the Baltic Proper stations $(n=19)$.

Marginal DistLM was used to determine the contribution of each predictor to the macrobenthic species composition, BQI and $M$. affinis abundance when other predictors are ignored. The variables included in the final DistLM output were selected using the stepwise selection procedure, which utilizes all possible combinations of the explanatory variables to determine the combination accounting for the best improvement of the Akaike information criterion corrected for a small sample size, AICc. To confirm that results were robust to the criteria used, we also performed the DistLM analyses with forward and backward selection and adjusted $\mathrm{R}^{2}$ as a stop criterion instead of AICc. The multivariate model (macrobenthic community) was visualized using a db-RDA (McArdle and Anderson, 2001). Finally, since organic carbon content and contaminant levels were highly correlated (Supplementary Table 7), we performed distLM analyses for the three models (macrobenthic species composition, M. affinis and BQI) with the variables $\mathrm{PAH}$ and metals that were force-excluded to compare the results between the concurrent models using the percentage of the overall variance explained.

\section{Step 3. Predictive Modelling}

To determine whether there was a significant relationship between the species composition and each environmental variable, a canonical analysis of principal coordinates, or CAP (Anderson and Robinson, 2003; Anderson and Willis, 2003) was applied. This allows a constrained ordination on the basis of, e.g., Bray-Curtis similarity, determining the axes that best discriminates an environmental gradient. A separate CAP analysis was done for each dependent variable (Ellis et al., 2015).

\section{RESULTS}

\section{Biotic Gradients}

In total, 17 species were recorded from the 29 stations (Table $\mathbf{1}$ ), with 3 to 11 species per station (Supplementary Table 2). Densities of the three most abundant macrobenthic species, i.e., the sentinel amphipod Monoporeia affinis, the tellenid bivalve Limecola balthica, and the non-indigenous polychaetes Marenzelleria spp., ranged from $10-30$ ind $\mathrm{m}^{-2}$ to 2,500 3,900 per $\mathrm{m}^{-2}$, with species-specific median densities of 825 (M. affinis), 687 (L. balthica), and 1271 (Marenzelleria spp.). Species composition with details on covariation among species is shown in Figure 2A.

There was no significant effect of neither Year nor Year $x$ Region interaction for macrobenthic species composition (Supplementary Figure 2 and Supplementary Table 8). By contrast, the effect of Region on the species composition was significant; differences between the regions were found both within and across basins (Supplementary Figure 2 and 
TABLE 1 | Species list of the 29 stations with species dominance and frequency of occurrence (number of stations with recorded species).

\begin{tabular}{|c|c|c|c|c|}
\hline \multirow{2}{*}{$\begin{array}{l}\text { Phylum } \\
\text { Annelida }\end{array}$} & \multirow{2}{*}{$\begin{array}{c}\text { Species } \\
\text { Bylgides sarsi }\end{array}$} & \multirow{2}{*}{$\begin{array}{c}\begin{array}{c}\text { Species } \\
\text { contribution }\end{array} \\
2 \%\end{array}$} & \multicolumn{2}{|c|}{ Frequency stations } \\
\hline & & & 14 & $(48 \%)$ \\
\hline & Marenzelleria spp. & $33 \%$ & 29 & $(100 \%)$ \\
\hline & Oligochaeta & $<1 \%$ & 9 & (31\%) \\
\hline & Pygospio elegans & $1 \%$ & 6 & $(21 \%)$ \\
\hline & Terebellides stroemi & $<1 \%$ & 1 & (3\%) \\
\hline \multirow[t]{6}{*}{ Arthropoda } & Chironomidae & $<1 \%$ & 2 & $(7 \%)$ \\
\hline & $\begin{array}{l}\text { Corophium } \\
\text { volutator }\end{array}$ & $<1 \%$ & 2 & $(7 \%)$ \\
\hline & Gammarus spp. & $<1 \%$ & 2 & $(7 \%)$ \\
\hline & Monoporeia affinis & $27 \%$ & 29 & $(100 \%)$ \\
\hline & $\begin{array}{l}\text { Pontoporeia } \\
\text { femorata }\end{array}$ & $14 \%$ & 16 & $(55 \%)$ \\
\hline & Saduria entomon & $1 \%$ & 19 & $(66 \%)$ \\
\hline \multirow[t]{4}{*}{ Mollusca } & Limecola balthica & $17 \%$ & 26 & $(90 \%)$ \\
\hline & Mya arenaria & $<1 \%$ & 1 & $(3 \%)$ \\
\hline & Mytilus edulis & $3 \%$ & 7 & $(24 \%)$ \\
\hline & $\begin{array}{l}\text { Potamopyrgus } \\
\text { antipodarum }\end{array}$ & $<1 \%$ & 1 & $(3 \%)$ \\
\hline Nemertea & Nemertea & $<1 \%$ & 2 & $(7 \%)$ \\
\hline Priapulida & $\begin{array}{l}\text { Halicryptus } \\
\text { spinulosus }\end{array}$ & $2 \%$ & 19 & $(66 \%)$ \\
\hline
\end{tabular}

The most common species were Marenzelleria spp., Monoporeia affinis and Limecola balthica. See Supplementary Table 2 for species list with abundance per $m^{2}$ per station.

Supplementary Table 9). The Region effect on the beta diversity was not significant (Permdisp $\mathrm{F}_{7,21}$ : 4.2753, $p<0.09$ ).

The BQI values at all stations except two (both in the southern Bothnian Sea, Figure 3) reached the threshold of good environmental status (assessment of a water body should however be based on at least five stations, see Leonardsson et al., 2009). The BQI index was significantly positively correlated with the abundance of $M$. affinis, $H$. spinulosus and P. femorata (Supplementary Table 10).

\section{Environmental Gradients}

Salinity differed between the basins, with average values 5.5 (range 5.2-5.8) and 6.5 (5.8-7.1) at the BoS and BP stations, respectively. The corresponding values for temperature were 5.2 $\left(2.3-8.8^{\circ} \mathrm{C}\right)$ and $8.0^{\circ} \mathrm{C}\left(4.8-11.8^{\circ} \mathrm{C}\right)$ in $\mathrm{BoS}$ and $\mathrm{BP}$, respectively. The other variables were not significantly different with regard to basin factor, thus, showing no clear latitudinal gradients (Supplementary Table 1). To summarise, the range in oxygen concentrations for the BoS and BP basins were 6.7-8.1 and 6.7$7.4 \mathrm{mg} \mathrm{O}_{2} \mathrm{~L}^{-1}$; organic carbon content in sediment was 0.3-2.7 and $0.3-6.1 \%$ of dwt and summer surface water Chl- $a$ 1.6-5.0 and 2.0-6.3 $\mathrm{mg} \mathrm{L}^{-1}$, respectively. The overall correlations between the environmental variables can be seen in Figure $\mathbf{2 B}$ and univariate correlations in Supplementary Table 7. Org C\% was significantly positively correlated to metal RQ and sum PAHs, while the temperature was significantly negatively correlated to metal RQ.

PAH concentrations were classified as medium to high values according to national guidelines at 4 stations (Josefsson, 2017); in addition, 8 stations exceeded the pristine level (Supplementary Table 1). Metals exceeded the total RQ (of 10) at 7 stations. The effect-based threshold values (EQS $\mathrm{Eediment})$ for fluoranthene was never exceeded, foranthracene it was exceeded at the southernmost station (BP-8.1). Eight stations in the Baltic Proper and one station in the Bothnian Sea had similar or higher values than $\mathrm{EQS}_{\text {sediment }}$ for bensofluor(b and $\mathrm{k}$ )anthen and the EQS $_{\text {sediment }}$ for benso(a)pyrene was exceeded at 3 stations in the Baltic proper. Concentrations of $\mathrm{Pb}$ and $\mathrm{Cd}$ were always below the $\mathrm{EQS}_{\text {sediment }}$.

\section{Macrobenthic Data Explained by Environmental Data}

The best-fit models generated by the DistLM analyses for 1) multivariate macrobenthic species composition data, 2)
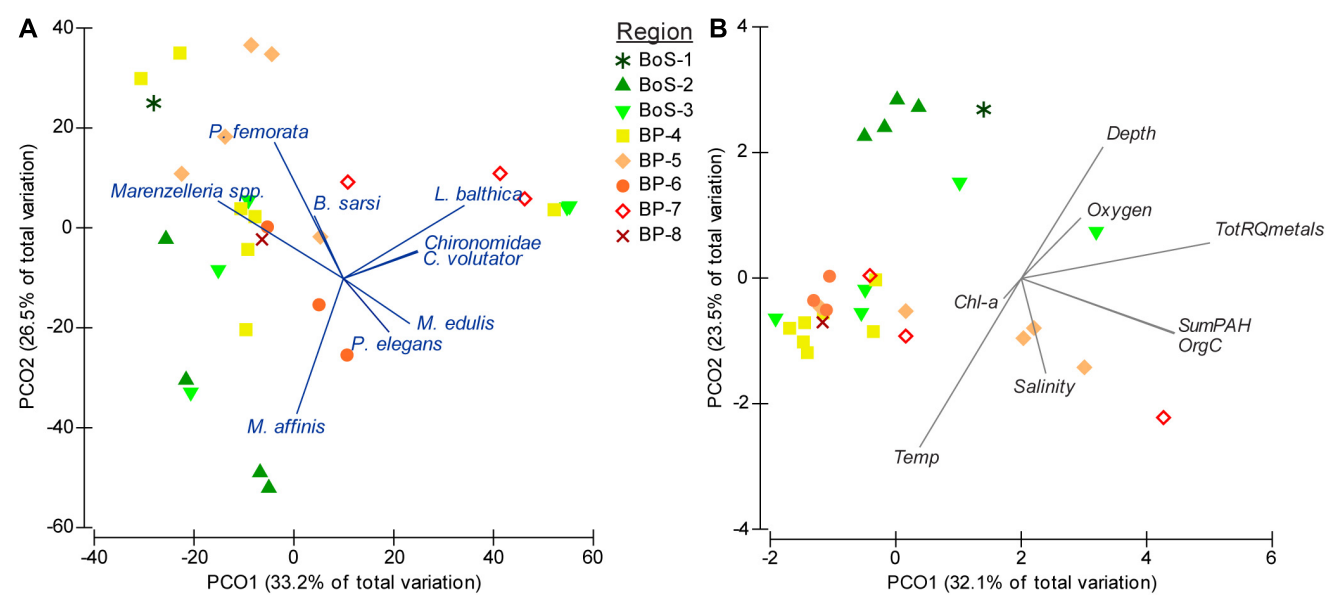

FIGURE 2 | Principal coordinate analysis PCO for year 2012 on (A) biological data (Bray-Curtis similarity on abundance data, untransformed), and (B) environmental and chemical data (Euclidean distance). See Table $\mathbf{1}$ for a complete list of abundance and occurrence of all species and Supplementary Table $\mathbf{2}$ for the station-specific list. 


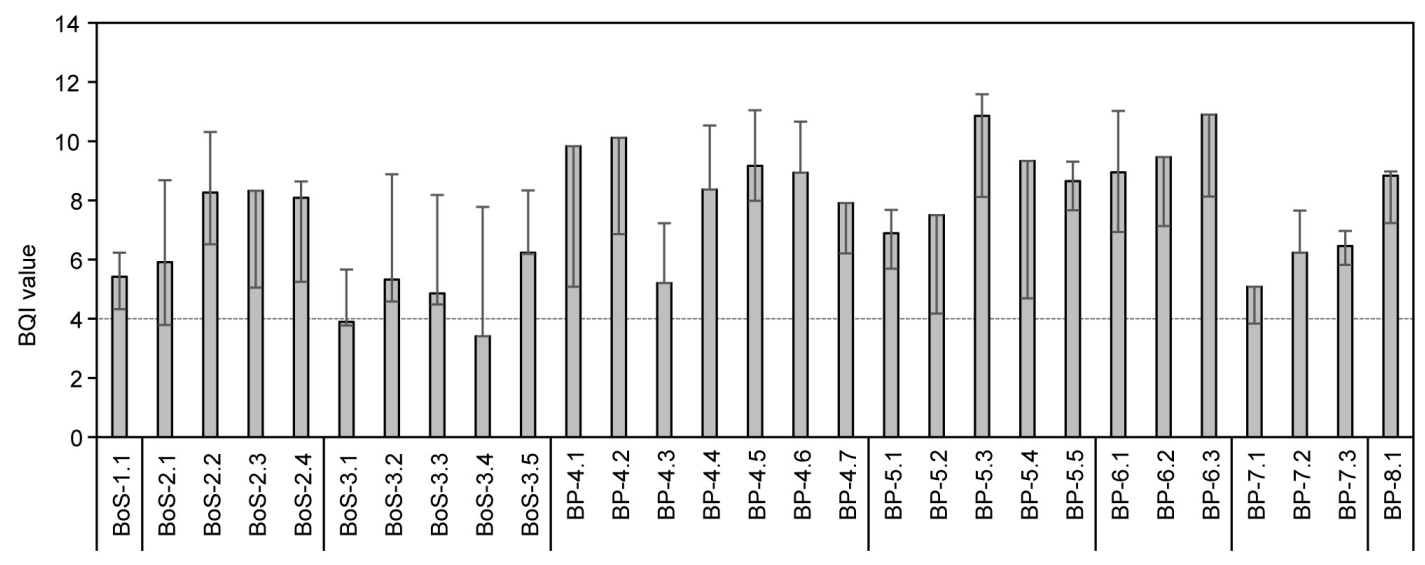

FIGURE 3 | BQI values for each station for the year 2012, error bars show max and min values for the period 2011-2014. The horizontal dashed line is the threshold for good ecological quality assessment (added for comparison but please note that assessment of a water body should be based on at least five stations, see Leonardsson et al., 2009).

TABLE 2 | DistLM output from sequential tests for the models for community composition, BQI and $M$. affinis abundance based on stepwise selection and AICc as stop criteria (see text).

\begin{tabular}{|c|c|c|c|c|c|c|c|c|}
\hline & Variable & $\mathrm{AICc}$ & SS(trace) & Pseudo-F & $P$-value & Prop. & Cumul. & res.df \\
\hline \multirow[t]{4}{*}{ Community composition } & Depth & 217.94 & 9375.3 & 5.55 & 0.0003 & $17 \%$ & $17 \%$ & 27 \\
\hline & Salinity & 216.21 & 6179.4 & 4.07 & 0.0013 & $11 \%$ & $28 \%$ & 26 \\
\hline & Temp. & 215.96 & 3824.8 & 2.68 & 0.0211 & $7 \%$ & $35 \%$ & 25 \\
\hline & SumPAH & 215.67 & 3762.3 & 2.83 & 0.0153 & $7 \%$ & $42 \%$ & 24 \\
\hline \multirow[t]{4}{*}{ BQI } & Salinity & 39.17 & 22.9 & 6.45 & 0.0177 & $19 \%$ & $19 \%$ & 27 \\
\hline & SumPAH & 33.04 & 24.7 & 9.02 & 0.0035 & $21 \%$ & $40 \%$ & 26 \\
\hline & Depth & 30.01 & 12.8 & 5.46 & 0.0263 & $11 \%$ & $51 \%$ & 25 \\
\hline & Temp. & 29.26 & 7.0 & 3.27 & 0.0855 & $6 \%$ & $57 \%$ & 24 \\
\hline M. affinis & SumPAH & 215.97 & 9126.9 & 5.78 & 0.0042 & $18 \%$ & $18 \%$ & 27 \\
\hline
\end{tabular}

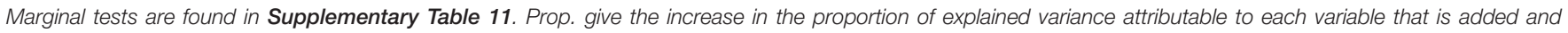

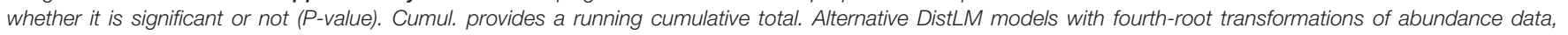
log-transformed PAHs and PAHs force-excluded are found in Supplementary Table 12. The final model outputs from all models are summarized in Table 3.

abundance of M. affinis, and 3) the BQI index, are summarized in Table 2; marginal tests are reported in Supplementary Table 11. The same explanatory variables (salinity, depth, temperature, and $\mathrm{PAH}$ concentrations), albeit in different order of importance, were included in the species composition model and the BQI model; they all were significant, except for temperature in the BQI model. The M. affinis abundance was best explained by the sumPAHs as a single predictor. In the models with PAHs and metals force-excluded, organic carbon replaced PAH as a fourth (community data) and second (BQI) most influential predictors and the only predictor for M. affinis. However, the total variance explained was lower in the two models (35\% for the community, and $15 \%$ for $M$. affinis; Table 3 ) compared to the models allowing $\mathrm{PAH}$ as a possible predictor. The BQI model was not affected (58 instead of $57 \%$ ) by adding a fifth variable instead of four variables when the PAHs variable was included (Supplementary Table 12).

When spring Chl- $a$ was considered as a possible predictor in addition to the summer Chl- $a$ and the other environmental variables (only possible for Baltic Proper, see methods), the DistLM analysis resulted in a final model with depth and sumPAH as predictors (Supplementary Table 13).
The correlation between $\mathrm{PAH}$ and the response variables (BQI and $M$. affinis) were negative, while salinity was positively correlated to BQI. A db-RDA is illustrating the relationships between species and environmental variables for the macrobenthic species composition model (Figure 4).

In the CAP analyses, a significant community change was observed along the PAH gradient (Figure 5, $\mathrm{R}^{2}=0.34, p<0.04$ ); however, correlations with salinity $\left(\mathrm{R}^{2}=0.70, p<0.001\right)$, temperature $\left(\mathrm{R}^{2}=0.49, p<0.015\right)$ and depth $\left(\mathrm{R}^{2}=0.52\right.$, $p<0.001)$ were stronger and more significant. Correlations with the other variables were not significant (org C: $\mathrm{R}^{2}=0.29, p>0.08$, oxygen: $\mathrm{R}^{2}=0.23, p>0.08$, Chl- $a: \mathrm{R}^{2}=0.07, p>0.6$, metals: $\left.\mathrm{R}^{2}=0.39, p>0.08\right)$.

\section{DISCUSSION}

This study shows that at reference stations within the Swedish macrobenthic monitoring program along the Baltic Sea coast, concentrations of 11 priority congeners of PAHs in sediment often exceed the level "low" in the national guidelines 
TABLE 3 | Summary of the cumulative proportion explained for each DistLM model (community composition, BQI and $M$. affinis); when abundance data was untransformed and fourth-root transformed, when all environmental variables initially included were untransformed and when PAHs and RQmetals were $\log (x+1)$-transformed, and, finally when the variable PAHs was force-excluded (due to its high correlation with orgC\%).

\begin{tabular}{|c|c|c|c|c|c|c|}
\hline & \multicolumn{3}{|c|}{ No transf. } & \multicolumn{3}{|c|}{ 4rt transf. } \\
\hline & $\begin{array}{l}\text { All variables, } \\
\text { no transf. }\end{array}$ & $\begin{array}{l}\text { All variables, } \mathrm{PAH} \text { and } \\
\text { metals Log }+1 \text { transf. }\end{array}$ & $\begin{array}{l}\text { PAH force- } \\
\text { excluded }\end{array}$ & $\begin{array}{l}\text { All variables, } \\
\text { no transf. }\end{array}$ & $\begin{array}{l}\text { All variables, PAH and } \\
\text { metals Log }+1 \text { transf. }\end{array}$ & $\begin{array}{l}\text { PAH force- } \\
\text { excluded }\end{array}$ \\
\hline Community comp. & $42 \%$ & $46 \%$ & $35 \%$ & $55 \%$ & $56 \%$ & $50 \%$ \\
\hline $\mathrm{BQI}$ & $57 \%$ & $60 \%$ & $58 \%$ & $59 \%$ & $62 \%$ & $55 \%$ \\
\hline M. affinis & $18 \%$ & $21 \%$ & $15 \%$ & $28 \%$ & $34 \%$ & $9 \%$ \\
\hline
\end{tabular}

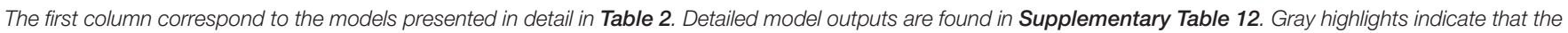
final model have added more variables than the "control" model in the first column (Table 2).

(Josefsson, 2017). Our analysis suggests that PAHs, together with non-chemical factors, such as salinity, temperature and depth, contribute significantly to variation in the macrobenthic species composition. Moreover, the same combinations of predictors explained the Benthic Quality Index (BQI) variation, indicating that BQI adequately represents the macrobenthic community state. Interestingly, the sum of PAHs alone was the best negative predictor of Monoporeia affinis abundance. The importance of PAHs in explaining changes in macrobenthic species composition and abundance of $M$. affinis suggests that populations and communities in sea areas with no known point sources of pollution are adversely affected by these environmental contaminants.

The positive relationship between PAHs and organic carbon (orgC\%) in sediment was expected because these compounds, especially high-molecular weight (hmw) PAHs, are lipophilic and sorb to organic particles associated with the sediment. However, after the force-exclusion of PAHs and replacing it with orgC, the models for both community

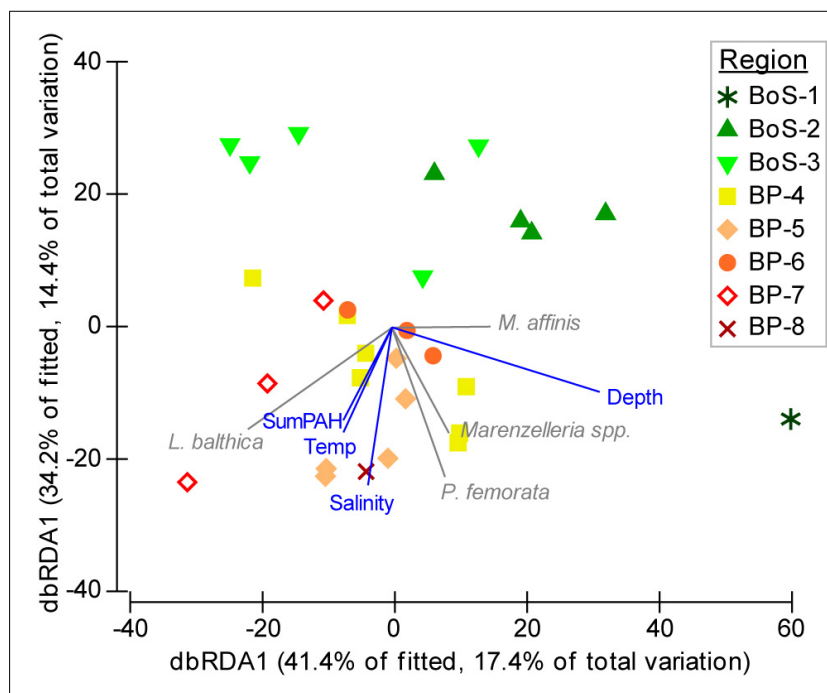

FIGURE 4 | db-RDA with the first two axes explaining $31.8 \%$ of the total variation. Environmental data selected in the best distLM model (Table 2) are shown as vectors (blue) and species characterizing the stations (gray) are overlaid to facilitate the interpretation. composition and M. affinis abundance as dependent variables were weaker. Thus, PAHs had greater explanatory capacity than organic carbon. The environmental quality standards $\left(\mathrm{EQS}_{\text {sediment }}\right)$ threshold value was exceeded for anthracene in one station (the southernmost). Furthermore, high concentrations relative to the indicative EQS values of other PAHs listed as priority substances under the EU Water Framework Directive, WFD (Council directive 2000/60/EC, 2000) - benzo[b and k]fluoranthene and benzo[a]pyrene were found at several stations in the Baltic Proper. High sediment concentrations of these PAHs have previously been reported in other Baltic areas without known point sources (Pikkarainen, 2004b); however, other PAHs, e.g., chrysene, pyrene, benzo $[a]$ anthracene and fluoranthene bioaccumulated most in the clam L. balthica inhabiting these sediments (Pikkarainen, 2004a). Thus, the sediment concentrations do not necessarily translate into body concentrations in macrobenthos because of the variability in bioavailability (driven by sediment properties, grain size distribution, and organic content, etc.) and physiological/biochemical properties of the organisms.

PAHs mainly affect invertebrates via narcosis, i.e., nonspecific toxicity (Douben, 2003), endocrine disruption, and genotoxicity (White et al., 1997; Douben, 2003; Zhang et al., 2016; Gorokhova et al., 2020). A majority of PAHs (19 out of 24) have shown positive correlations to various reproductive disorders in $M$. affinis, especially to the occurrence of dead broods (Löf et al., 2016). Macrobenthic species can, however, respond to PAH exposure in different ways. Following the large Tsesis oil spill in 1977 that took place in the Baltic Sea archipelago, close to the Askö area, where several of the highest concentrations were also measured in this study, the bivalve L. balthica population was relatively unaffected despite the considerable contamination by oil hydrocarbons. Conversely, the amphipods $M$. affinis and $P$. femorata showed drastically reduced population densities for at least three years after the accident, as well as increased malformed embryos (Elmgren et al., 1983). The macrobenthic species composition may, therefore, at least partly, reflect contaminant history in the area.

Metals were not identified as significant predictors despite the high RQ values of metals at several stations, suggesting that their effects were low compared to PAHs. Heavy metals should not, however, be dismissed as a potential toxicity source to the benthos. Copper, zinc, and lead at levels below 


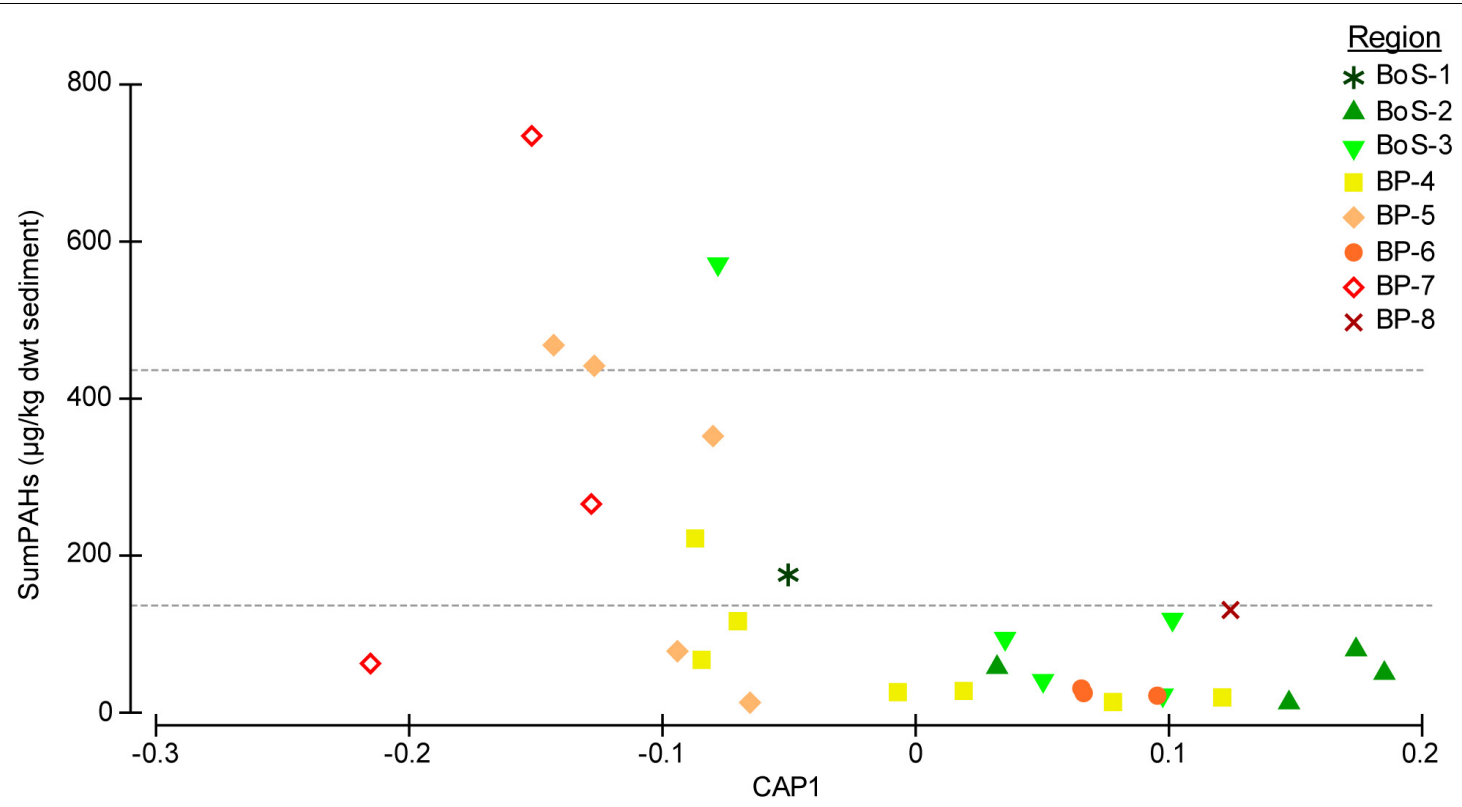

FIGURE 5 | CAP axis 1 correlated with PAH concentrations (sum of the 11 priority PAHs). Horizontal dashed lines represent the classification for PAH contamination in relation to pristine status and based on the Swedish EPA guidelines (SEPA, 1999; Josefsson, 2017); the thresholds are set to 170 and 440 representing thresholds between very low to low levels and low to medium high levels, respectively.

sediment quality guidelines in New Zealand and Australia have been linked to altered benthic community composition and a decline in large species, i.e., infaunal bivalves (Hewitt et al., 2009). In shallow Baltic harbors with zinc and copper concentrations comparable to those measured in our study, gastropods suffered sublethal effects as well as increased mortality (Bighiu et al., 2017a,b). In the EU WFD, mercury, cadmium and lead are considered priority substances (Council directive 2000/60/EC, 2000); these metals are particularly toxic to crustaceans (e.g., Connor, 1972; Greenwood and Fielder, 1983; Giudici and Guarino, 1989; Reddy et al., 1997; Itow et al., 1998). The measured values in our study was below the $\mathrm{EQS}_{\text {sediment }}$ values for cadmium and lead, however, cadmium concentrations comparable to those in our study were found to increase embryo aberrations in M. affinis (Sundelin, 1983; Löf et al., 2016).

Despite the fact that the Baltic Sea is considered one of the most contaminated sea areas in the world (Reusch et al., 2018), sediment contaminants have not previously been included in models of macrobenthic species composition from sites that are not directly affected by pollution. Depauperate macrobenthic communities in heavily contaminated areas compared to reference sites have, however, been reported in the southern Baltic Sea (Bettinetti et al., 2009). Exposure to multiple stressors, e.g., contaminated sediments and hypoxia, can lead to a decreased capacity to cope with these stressors, as shown for M. affinis (Gorokhova et al., 2010, 2013). In our study, none of the environmental variables linked to the eutrophication, i.e., oxygen concentrations in the bottom water, the organic carbon content of sediment and water column chlorophyll-a during summer and spring, were identified as significant predictors for any of the three response variables: species composition, the BQI index and abundance of the sentinel species $M$. affinis. This raises concerns about using BQI (or benthic community composition in general) as eutrophication indicators and highlights the problem of evaluating anthropogenic pressures in isolation. Based on the correlation between BQI and contaminants (PAHs) found in this study, we believe that the species sensitivity values in the BQI calculation need an update to include ecotoxicological sensitivity to account for other types of disturbances than eutrophication only.

Our results suggest that Baltic macrobenthic communities, even in the relatively unpolluted areas, are impacted by anthropogenic contaminants. This impact may need to be accounted for when macrobenthos is used as an indicator of eutrophication. However, long-term contaminant data in sediments are very limited as well as the spatial coverage for macrobenthos community data. To investigate the contaminants in the open sea, the national Swedish status and trend monitoring programme for contaminants in marine sediments was launched in 2003, with 16 offshore stations (12 within the Baltic Sea) and sampling every 5-6 years (Apler and Josefsson, 2016). Unfortunately, six of the 8 stations in the Baltic Proper in this monitoring are located at depths where macrobenthos is absent due to anoxic conditions; hence, the data on the contaminant concentrations have relatively low spatial overlap with the biological data collected within Swedish benthic monitoring programs. Better coordination between the monitoring programs would facilitate the contribution of PAHs (and, probably, other contaminants) in combination with eutrophication to community responses at a larger scale if we are to use changes in the macrobenthic species composition, dynamics of the sentinel 
amphipod M. affinis, and, ultimately, BQI for environmental quality assessment.

\section{DATA AVAILABILITY STATEMENT}

The original contributions presented in the study are included in the article/Supplementary Material, further inquiries can be directed to the corresponding author/s.

\section{AUTHOR CONTRIBUTIONS}

AK designed the study and together with CR compiled the data and drafted the manuscript. CR performed all the final statistical analyses. EG provided data on PAHs and contributed to the manuscript writing. All authors contributed to the article and approved the submitted version.

\section{FUNDING}

Metal analyses was funded by The King Carl XVI 50-year Foundation for Science, Technology and Environment to AK.

\section{REFERENCES}

Anderson, M. J. (2001). A new method for non-parametric multivariate analysis of variance. Austral. Ecol. 26, 32-46. doi: 10.1111/j.1442-9993.2001.01070.pp.x

Anderson, M. J., Ellingsen, K. E., and McArdle, B. H. (2006). Multivariate dispersion as a measure of beta diversity. Ecol. Lett. 9, 683-693. doi: 10.1111/ j.1461-0248.2006.00926.x

Anderson, M. J., Gorley, R. N., and Clarke, K. R. (2008). PERMANOVA+ for PRIMER: Guide to Software and Statistical Methods. Plymouth, UK: PRIMER-E.

Anderson, M. J., and Robinson, J. (2003). Generalized discriminant analysis based on distances. Austral. N. Zeal. J. Stat. 45, 301-318. doi: 10.1111/1467-842x. 00285

Anderson, M. J., and Willis, T. J. (2003). Canonical analysis of principal coordinates: a useful method of constrained ordination for ecology. Ecology 84, 511-525. doi: 10.1890/0012-9658(2003)084[0511:caopca]2.0.co;2

Ankar, S., and Elmgren, R. (1976). The Benthic Macro- and Meiofauna of the AsköLandsort Area (Northern Baltic Proper). A Stratified Sampling Survey. Askö Laboratory no 11. Sweden: Univ of Stockholm.

Apler, A., and Josefsson, S. (2016). Swedish Status and Trend Monitoring Programme. Chemical contamination in offshore sediments 2003 - 2014. Report no. 2016:04. Uppsala: Geological Survey of Sweden (SGU).

Arias-Andres, M., Ramo, R., Torres, F. M., Ugalde, R., Grandas, L., Ruepert, C., et al. (2018). Lower tier toxicity risk assessment of agriculture pesticides detected on the Rio Madre de Dios watershed, Costa Rica. Environ. Sci. Pollut. Res. 25, 13312-13321. doi: 10.1007/s11356-016-7875-7

Axelman, J., Näf, C., Bandh, C., Ishaq, R., Pettersen, H., Zebühr, Y., et al. (2001). "Dynamics and distribution of hydrophobic organic compounds in the Baltic Sea," in A systems analysis of the Baltic Sea, eds F. Wulff, L. Rahm, and P. Larsson (Berlin: Springer-Verlag), 257-287. doi: 10.1007/978-3-662-04453-7_10

Bastrop, R., and Blank, M. (2006). Multiple invasions - a polychaete genus enters the Baltic Sea. Biol. Invasions 8, 1195-1200. doi: 10.1007/s10530-005-6186-6

Belkin, I. M. (2009). Rapid warming of large marine ecosystems. Prog. Oceanogr. 81, 207-213. doi: 10.1016/j.pocean.2009.04.011

Bettinetti, R., Galassi, S., Falandysz, J., Camusso, M., and Vignati, D. A. L. (2009). Sediment quality assessment in the gulf of gdansk (Baltic Sea) using complementary lines of evidence. Environ. Manag. 43, 1313-1320. doi: 10.1007/ s00267-008-9267-3
The collection of sediments and PAH analyses were funded via project ReproIND (FORMAS) and the national program for biological effect monitoring of contaminants and INSERT project (Swedish Environmental Protection Agency) to EG. The Swedish national and regional benthic monitoring program is funded by the Swedish Agency for Marine and Water Management (Havs och Vattenmyndigheten) and the county administrative board (Länsstyrelsen).

\section{ACKNOWLEDGMENTS}

We thank Matias Ledesma (Stockholm University) for compiling the environmental data from DAS. Jan Albertsson (Umeå University) and Mats Blomqvist (Hafok $\mathrm{AB}$ ) provided benthic data from the Bothnian Sea. Jonas Gunnarsson is acknowledged for comments on a previous draft.

\section{SUPPLEMENTARY MATERIAL}

The Supplementary Material for this article can be found online at: https://www.frontiersin.org/articles/10.3389/fenvs. 2021.624658/full\#supplementary-material

Bighiu, M. A., Gorokhova, E., Almroth, B. C., and Wiklund, A. K. E. (2017a). Metal contamination in harbours impacts life-history traits and metallothionein levels in snails. PLoS One 12:e180157. doi: 10.1371/journal.pone.0180157

Bighiu, M. A., Watermann, B., Guo, X. L., Almroth, B. C., and Eriksson-Wiklund, A. K. (2017b). Mortality and histopathological effects in harbour-transplanted snails with different exposure histories. Aquat. Toxicol. 190, 11-20. doi: 10. 1016/j.aquatox.2017.06.018

Borja, A., Franco, J., and Perez, V. (2000). A marine Biotic Index to establish the ecological quality of soft-bottom benthos within European estuarine and coastal environments. Mar. Pollut. Bull. 40, 1100-1114. doi: 10.1016/s0025-326x(00) 00061-8

Breitburg, D., Levin, L. A., Oschlies, A., Gregoire, M., Chavez, F. P., Conley, D. J., et al. (2018). Declining oxygen in the global ocean and coastal waters. Science 359, 46-78. doi: 10.1126/science.aam 7240

Carstensen, J., Andersen, J. H., Gustafsson, B. G., and Conley, D. J. (2014). Deoxygenation of the Baltic Sea during the last century. Proc. Natl. Acad. Sci. U.S.A. 111, 5628-5633. doi: 10.1073/pnas.1323156111

Clarke, K. R., and Gorley, R. N. (2006). PRIMER v6: User Manual/Tutorial. Plymouth: PRIMER-E.

Cloern, J. E., Abreu, P. C., Carstensen, J., Chauvaud, L., Elmgren, R., Grall, J., et al. (2016). Human activities and climate variability drive fast-paced change across the world's estuarine-coastal ecosystems. Glob. Change Biol. 22, 513-529. doi: $10.1111 /$ gcb.13059

Conley, D. J., Bjorck, S., Bonsdorff, E., Carstensen, J., Destouni, G., Gustafsson, B. G., et al. (2009). Hypoxia-related processes in the Baltic Sea. Environ. Sci. Technol. 43, 3412-3420. doi: 10.1021/es802762a

Conley, D. J., Carstensen, J., Aigars, J., Axe, P., Bonsdorff, E., Eremina, T., et al. (2011). Hypoxia is increasing in the coastal zone of the Baltic Sea. Environ. Sci. Technol. 45, 6777-6783. doi: 10.1021/es201212r

Connor, P. M. (1972). Acute toxicity of heavy metals to some marine larvae. Mar. Pollut. Bull. 3, 190-192. doi: 10.1016/0025-326x(72)90268-8

Council directive 2000/60/EC (2000). Directive 2000/60/EC of the European Parliament and of the Council of 23 October 2000 Establishing a Framework for Community Action in the Field of Water Policy. Brussels: EC.

CSN EN ISO 16665. (2013). Water Quality - Guidelines for Quantitative Sampling and Sample Processing of Marine Soft-Bottom Macrofauna (ISO 16665:2014). Brussels: European Standard. 
Dauer, D. M. (1993). Biological criteria, environmental-health and estuarine macrobenthic community structure. Mar. Pollut. Bull. 26, 249-257. doi: 10. 1016/0025-326x(93)90063-p

Douben, P. (2003). PAHs: An Ecotoxicological Perspective. Chichester: John Wiley \& Sons Ltd.

EC (2011). Technical Guidance for Deriving Environmental Quality Standards: Guidance Document. No 27, in Common Implementation Strategy for the Water Framework Directive (2000/60/EC), Guidance Document. Brussels: European Commission.

EFSA (2013). Guidance on tiered risk assessment for plant protection products for aquatic organisms in edge-of-field surface waters. EFSA J. 11:3290.

Ehrnsten, E., Norkko, A., Muller-Karulis, B., Gustafsson, E., and Gustafsson, B. G. (2020). The meagre future of benthic fauna in a coastal sea-Benthic responses to recovery from eutrophication in a changing climate. Glob. Change Biol. 16:15014. doi: $10.1111 / \mathrm{gcb} .15014$

Ellis, J. I., Hewitt, J. E., Clark, D., Taiapa, C., Patterson, M., Sinner, J., et al. (2015). Assessing ecological community health in coastal estuarine systems impacted by multiple stressors. J. Exp. Mar. Biol. Ecol. 473, 176-187. doi: 10.1016/j.jembe. 2015.09.003

Elmgren, R. (1984). Trophic dynamics in the enclosed, brackish Baltic Sea. Rapp. P.-V. Reun. Cons. Int. Explor. Mer. 184, 152-169.

Elmgren, R. (1989). Mans impact on the ecosystem of the Baltic Sea - energy flows today and at the turn of the century. Ambio 18, 326-332.

Elmgren, R., Hansson, S., Larsson, U., Sundelin, B., and Boehm, P. D. (1983). The Tsesis oil-spill - acute and long-term impact on the benthos. Mar. Biol. 73, 51-65. doi: 10.1007/bf00396285

Elmgren, R., and Hill, C. (1997). "Ecosystem function at low biodiversity - the Baltic example," in Marine Biodiversity: Patterns and Processes, eds R. F. G. Ormond and J. Gage (Cambridge, MA: Cambridge University Press), 319-336. doi: $10.1017 /$ cbo9780511752360.015

Gammal, J., Norkko, J., Pilditch, C. A., and Norkko, A. (2017). Coastal hypoxia and the importance of benthic macrofauna communities for ecosystem functioning. Estuar. Coasts 40, 457-468. doi: 10.1007/s12237-016-0152-7

Giudici, M. D., and Guarino, S. M. (1989). Effects of chronic exposure to cadmium or copper on Idothea-baltica (Crustacea, Isopoda). Mar. Pollut. Bull. 20, 69-73. doi: 10.1016/0025-326x(89)90229-4

Gorokhova, E., Lof, M., Halldorsson, H. P., Tjarnlund, U., Lindstrom, M., Elfwing, T., et al. (2010). Single and combined effects of hypoxia and contaminated sediments on the amphipod Monoporeia affinis in laboratory toxicity bioassays based on multiple biomarkers. Aquat. Toxicol. 99, 263-274. doi: 10.1016/j. aquatox.2010.05.005

Gorokhova, E., Lof, M., Reutgard, M., Lindstrom, M., and Sundelin, B. (2013). Exposure to contaminants exacerbates oxidative stress in amphipod Monoporeia affinis subjected to fluctuating hypoxia. Aquat. Toxicol. 127, 46-53. doi: 10.1016/j.aquatox.2012.01.022

Gorokhova, E., Martella, G., Motwani, N. H., Tretyakova, N. Y., Sundelin, B., and Motwani, H. V. (2020). DNA epigenetic marks are linked to embryo aberrations in amphipods. Sci. Rep. 10:11. doi: 10.1038/s41598-020-57465-1

Greenwood, J. G., and Fielder, D. R. (1983). Acute toxicity of zinc and cadmium to zoeae of three species of portunid crabs (crustacea: brachyura). Comp. Biochem. Physiol. C Comp. Pharmacol. 75, 141-144. doi: 10.1016/0742-8413(83)90024-5

Halpern, B. S., Walbridge, S., Selkoe, K. A., Kappel, C. V., Micheli, F., D'Agrosa, C., et al. (2008). A global map of human impact on marine ecosystems. Science 319, 948-952. doi: 10.1126/science.1149345

HELCOM (2009). "Eutrophication in the Baltic Sea - An integrated thematic assessment of the effects of nutrient enrichment and eutrophication in the Baltic Sea region," in Proceedings of the Balt. Sea Environ. Proc. No. 115B, (Finland: Helsinki Commission).

HELCOM (2010). "Hazardous substances in the Baltic Sea - An integrated thematic assessment of hazardous substances in the Baltic Sea," in Proceedings of the Balt. Sea Environ. Proc. No. 120B, (Finland: Helsinki Commission).

HELCOM (2018a). Reproductive Disorders: Malformed Embryos of Amphipods. Finland: HELCOM.

HELCOM (2018b). State of the Soft-Bottom Macrofauna Community. Finland: HELCOM.

Hewitt, J. E., Anderson, M. J., Hickey, C. W., Kelly, S., and Thrush, S. F. (2009). Enhancing the ecological significance of sediment contamination guidelines through integration with community analysis. Environ. Sci. Technol. 43, 21182123. doi: $10.1021 / \mathrm{es} 802175 \mathrm{k}$

Itow, T., Loveland, R. E., and Botton, M. L. (1998). Developmental abnormalities in horseshoe crab embryos caused by exposure to heavy metals. Arch. Environ. Contam. Toxicol. 35, 33-40. doi: 10.1007/s002449900345

Josefsson, S. (2017). Klassning av Halter av Organiska Föroreningar I Sediment. Report no. 2017:12. Uppsala: Geological Survey of Sweden (SGU).

Karlson, K., Rosenberg, R., and Bonsdorff, E. (2002). "Temporal and spatial large-scale effects of eutrophication and oxygen deficiency on benthic fauna in Scandinavian and Baltic waters - a review," in Oceanography and Marine Biology, Vol. 40, eds R. N. Gibson, M. Barnes, and R. J. A. Atkinson (London: Taylor \& Francis Ltd), 427-489. doi: 10.1201/9780203180594.ch8

Kauppi, L., Norkko, A., and Norkko, J. (2015). Large-scale species invasion into a low-diversity system: spatial and temporal distribution of the invasive polychaetes Marenzelleria spp. in the Baltic Sea. Biol. Invasions 17, 2055-2074. doi: 10.1007/s10530-015-0860-0

Landrum, P. F., Lotufo, G. R., Gossiaux, D. C., Gedeon, M. L., and Lee, J. H. (2003). Bioaccumulation and critical body residue of PAHs in the amphipod, Diporeia spp.: additional evidence to support toxicity additivity for PAH mixtures. Chemosphere 51, 481-489. doi: 10.1016/s0045-6535(02)00863-9

Leonardsson, K., Blomqvist, M., and Rosenberg, R. (2009). Theoretical and practical aspects on benthic quality assessment according to the EU-Water Framework Directive-examples from Swedish waters. Mar. Pollut. Bull. 58, 1286-1296. doi: 10.1016/j.marpolbul.2009.05.007

Leppäkoski, E., and Bonsdorff, E. (1989). "Ecosystem variability and gradients. examples from the baltic sea as a background for hazard assessment," in Chemicals in the Aquatic Environment, ed. L. Landner (Berlin: Springer).

Löf, M., Sundelin, B., Bandh, C., and Gorokhova, E. (2016). Embryo aberrations in the amphipod Monoporeia affinis as indicators of toxic pollutants in sediments: a field evaluation. Ecol. Indic. 60, 18-30. doi: 10.1016/j.ecolind.2015. 05.058

Long, E. R., Macdonald, D. D., Smith, S. L., and Calder, F. D. (1995). Incidence of adverse biological effects within ranges of chemical concentrations in marine and estuarine sediments. Environ. Manag. 19, 81-97. doi: 10.1007/bf02472006

Martins, V. A., Frontalini, F., Tramonte, K. M., Figueira, R. C. L., Miranda, P., Sequeira, C., et al. (2013). Assessment of the health quality of Ria de Aveiro (Portugal): heavy metals and benthic foraminifera. Mar. Pollut. Bull. 70, 18-33. doi: 10.1016/j.marpolbul.2013.02.003

McArdle, B. H., and Anderson, M. J. (2001). Fitting multivariate models to community data: a comment on distance-based redundancy analysis. Ecology 82, 290-297. doi: 10.1890/0012-9658(2001)082[0290:fmmtcd]2.0.co;2

Meier, H. E. M. (2007). Modeling the pathways and ages of inflowing salt- and freshwater in the Baltic Sea. Estuar. Coast. Shelf Sci. 74, 610-627. doi: 10.1016/j. ecss.2007.05.019

Muniz, P., Venturini, N., Pires-Vanin, A. M. S., Tommasi, L. R., and Borja, A. (2005). Testing the applicability of a Marine Biotic Index (AMBI) to assessing the ecological quality of soft-bottom benthic communities, in the South America Atlantic region. Mar. Pollut. Bull. 50, 624-637. doi: 10.1016/j. marpolbul.2005.01.006

Pearson, T. H., and Rosenberg, R. (1978). Macrobenthic succession in relation to organic enrichment and pollution of the marine environment. Oceanogr. Mar. Biol. Ann. Rev. 16, 229-311.

Perus, J., Bonsdorff, E., Bäck, S., Lax, H.-G., Villnäs, A., and Westberg, V. (2007). Zoobenthos as indicators of ecological status in coastal brackish waters: a comparative study from the Baltic Sea. AMBIO 36, 250-256. doi: 10.1579/00447447(2007)36[250:zaioes]2.0.co;2

Pikkarainen, A. L. (2004a). Polycyclic aromatic hydrocarbons in Baltic Sea bivalves. Polycyclic Arom. Compounds 24, 681-695. doi: 10.1080/10406630490472310

Pikkarainen, A. L. (2004b). Polycyclic aromatic hydrocarbons in Baltic Sea sediments. Polycyclic Arom. Compounds 24, 667-679. doi: 10.1080/ 10406630490472293

Reddy, P. S., Tuberty, S. R., and Fingerman, M. (1997). Effects of cadmium and mercury on ovarian maturation in the red swamp crayfish, Procambarus clarkii. Ecotoxicol. Environ. Saf. 37, 62-65. doi: 10.1006/eesa.1997.1523

Reusch, T. B. H., Dierking, J., Andersson, H. C., Bonsdorff, E., Carstensen, J., Casini, M., et al. (2018). The Baltic Sea as a time machine for the future coastal ocean. Sci. Adv. 4:eaar8195. doi: 10.1126/sciadv.aar8195 
Rousi, H., Laine, A. O., Peltonen, H., Kangas, P., Andersin, A. B., Rissanen, J., et al. (2013). Long-term changes in coastal zoobenthos in the northern Baltic Sea: the role of abiotic environmental factors. ICES J. Mar. Sci. 70, 440-451. doi: 10.1093/icesjms/fss197

Rumohr, H., Bonsdorff, E., and Pearson, T. H. (1996). Zoobenthic succession in Baltic sedimentary habitats. Arch. Fish. Mar. Res. 44, $179-213$.

Savchuk, O. P. (2018). Large-scale nutrient dynamics in the Baltic Sea, 1970-2010. Front. Mar. Sci. 5:20. doi: 10.3389/fmars.2018.00095

Segerstråle, S. G. (1960). Investigations on Baltic populations of the bivalve Macoma balthica (L.). Part 1. Introduction. Studies on recruitment and its relation to depth in Finnish coastal waters during the period 1922-1959. Age and growth. Soc. Sci. Fenn. Comm. Biol. 23:2.

SEPA (1999). Bedömningsgrunder för Miljökvalitet. Kust och hav. Naturvårdsverket rapport 4914. Uppsala: SEPA.

SEPA (2007). Bedömningsgrunder för Kustvatten Och Vatten i Övergångszon. Bilaga till Handbok 2007:4. Uppsala: SEPA.

Sokolov, A., Andrejev, O., Wulff, F., and Rodriguez Medina, M. (1997). The Data Assimilation System for Data Analysis in the Baltic Sea. Stockholm: Stockholm University.

Sundelin, B. (1983). Effects of cadmium on Pontoporeia-affinis (Crustacea, Amphipoda) in laboratory soft-bottom microcosms. Mar. Biol. 74, 203-212. doi: $10.1007 /$ bf00413923

Sundelin, B., and Eriksson, A. K. (1998). Malformations in embryos of the depositfeeding amphipod Monoporeia affinis in the Baltic Sea. Mar. Ecol. Prog. Ser. 171, 165-180. doi: 10.3354/meps171165
Sundelin, B., Eriksson Wiklund, A. K., and Ford, A. T. (2008). "Biological effects of contaminants: The use of embryo aberrations in amphipod crustaceans for measuring effects of environmental stressors," in Proceedings of the ICES Techniques in Marine Environmental Sciences no 41 (TIMES), Copenhagen.

Villnäs, A., and Norkko, A. (2011). Benthic diversity gradients and shifting baselines: implications for assessing environmental status. Ecol. Appl. 21, 21722186. doi: 10.1890/10-1473.1

White, P. A., Blaise, C., and Rasmussen, J. B. (1997). Detection of genotoxic substances in bivalve molluscs from the Saguenay Fjord (Canada), using the SOS chromotest. Mutation Res. Genet. Toxicol. Environ. Mutagenesis 392, 277-300. doi: 10.1016/s1383-5718(97)00082-x

Zhang, Y. Y., Dong, S. J., Wang, H. G., Tao, S., and Kiyama, R. (2016). Biological impact of environmental polycyclic aromatic hydrocarbons (ePAHs) as endocrine disruptors. Environ. Pollut. 213, 809-824. doi: 10.1016/j.envpol. 2016.03.050

Conflict of Interest: The authors declare that the research was conducted in the absence of any commercial or financial relationships that could be construed as a potential conflict of interest.

Copyright (C) 2021 Raymond, Gorokhova and Karlson. This is an open-access article distributed under the terms of the Creative Commons Attribution License (CC BY). The use, distribution or reproduction in other forums is permitted, provided the original author(s) and the copyright owner(s) are credited and that the original publication in this journal is cited, in accordance with accepted academic practice. No use, distribution or reproduction is permitted which does not comply with these terms. 